\title{
Diálogos interprofissionais e interdisciplinares na prática extensionista: o caminho para a inserção do conceito ampliado de saúde na formação acadêmica
}

Interprofessional and interdisciplinary dialogues in university extension: a pathway towards incorporating a broader concept of health into academic education (abstract: p. 20)

Diálogos interprofesionales e interdisciplinarios en la práctica extensionista: el camino para la inserción del concepto ampliado de salud en la formación académica (resumen: p. 20)

\section{David Ramos da Silva Rios ${ }^{(a)}$}

<david-rios@hotmail.com> (iD

Daniel Andrade Barreto de Sousa ${ }^{(b)}$

<dan-barreto@hotmail.com>

Maria Constantina Caputo(c)

<caputo@ufba.br> iD

\author{
(a) Pós-graduando do Programa de \\ Residência Médica em Medicina \\ da Família e Comunidade \\ (Especialização), Complexo \\ Hospitalar Universitário Professor \\ Edgard Santos, Universidade Federal \\ da Bahia (UFBa). Rua Barão de \\ Jeremoabo, s/no, PAF V, Sala 209, \\ Ondina. Salvador, BA, Brasil. 40170- \\ 115. \\ (b) Pós-graduando do Programa de \\ Residência Médica em Medicina \\ da Família e Comunidade \\ (Especialização), Fundação Estatal \\ de Saúde da Família. Salvador, BA, \\ Brasil. \\ (c) Bacharelado Interdisciplinar em \\ Saúde, Instituto de Humanidades, \\ Artes e Ciências Prof. Milton Santos, \\ UFBa. Salvador, BA, Brasil.
}

O presente artigo discute a importância da interdisciplinaridade e da interprofissionalidade no processo de formação em saúde, partindo da compreensão de que não é possível concretizar uma visão ampla da saúde nos moldes do conhecimento disciplinar e uniprofissional. Trata-se de uma pesquisa exploratória de abordagem qualitativa que se baseou em entrevistas semiestruturadas realizadas com discentes de duas universidades, participantes de uma atividade de extensão realizada no assentamento Baixão, localizado na região centro-sul da Bahia, Brasil. A análise dos dados utilizou a metodologia da análise de conteúdo. A partir das entrevistas, compreende-se que as atividades de extensão possuem o potencial de transformar o processo formativo dos sujeitos envolvidos, seja em seus aspectos profissionais ou pessoais. Conclui-se que ações extensionistas possibilitam a construção de novos espaços, nos quais é possível desenvolver a interação e o compartilhamento de saberes, bem como práticas colaborativas.

Palavras-chave: Relações comunidade-instituição. Práticas interdisciplinares. Educação superior. 
(2)

\section{De que saúde nós estamos falando?}

Em sentido mais abrangente, a saúde é resultante das condições de alimentação, habitação, educação, renda, meio ambiente, trabalho, transporte, emprego, lazer, liberdade, acesso e posse da terra e acesso aos serviços de saúde. É, assim, antes de tudo o resultado das formas de organização social, de produção, as quais podem gerar grandes desigualdades nos níveis de vida ${ }^{1}$. (p. 4)

A compreensão da saúde por meio do seu conceito ampliado é historicamente recente. Ela se desenvolveu em diversos países da América Latina, em um contexto sócio-político de luta por direitos entre os anos 1970 e 1980, contrapondo-se às concepçôes de saúde centradas na doença² ${ }^{2}$.

A noção de saúde como "não doença" foi reafirmada pelas ciências médicas durante muito tempo, principalmente no período de fortalecimento do método científico. No início do século XIX, observou-se o fortalecimento da racionalidade científica à compreensão dos fenômenos da humanidade e da natureza, em detrimento de outras formas de conhecimento até então consideradas válidas. Essa racionalidade baseia-se em princípios, do que ficou conhecido como paradigma cartesiano, como o da separação - segundo o qual, para estudar um fenômeno ou resolver um problema, é preciso decompô-lo em elementos simples - e o da redução - segundo o qual é preciso reduzir o fenômeno àquilo que é mensurável e quantificável ${ }^{3}$.

$\mathrm{Na}$ medida em que os princípios norteadores da ciência moderna hegemonizamse no campo da saúde, observa-se a ênfase no conhecimento experimental de base subindividual, reforçando, portanto, a separação entre individual e coletivo; privado e público; biológico e social; e curativo e preventivo ${ }^{4}$. Assim, estruturam-se conhecimentos cada vez mais específicos sobre cada função e disfunção orgânica, por meio da segmentação do corpo humano, desde o estudo dos sistemas orgânicos até as mais novas descobertas sobre os componentes e compartimentos subcelulares. Há ainda a fragmentação do saber em diversas disciplinas incomunicantes e, por conseguinte, a valorização da especialização e subespecialização profissional ${ }^{5}$.

Esse modus operandi pôs ênfase na compreensão dos aspectos biológicos do adoecimento, concentrando ações à identificação e análise das doenças e suas correspondentes terapêuticas; e secundarizando o conceito de saúde, que foi implicitamente compreendido como oposto lógico à doença, resultando em abordagens restritas ao plano individual e às práticas curativas. Há de se reconhecer que ele trouxe diversos avanços à sociedade e à própria ciência, como o aumento da expectativa de vida da população a partir do controle de doenças infecto-contagiosas ${ }^{6}$. Entretanto, esse reducionismo biocêntrico apresentou uma série de limitações na proposição de respostas às questóes que se manifestavam em contextos mais amplos, como as que circunscrevem a saúde em sua dimensão coletiva.

Com o surgimento da saúde pública, que se estabelece como campo científico ao longo do século XX, o enfoque biomédico entra em tensão com enfoques sociopolíticos e ambientais, também considerados no entendimento do adoecer. Desse modo, é possível observar ao longo do tempo o surgimento de alguns paradigmas explicativos para o processo saúde-doença, a saber: a saúde como ausência de doenças; a 
saúde como bem-estar; a saúde em sua dimensão normativa e de controle dos corpos; e a saúde como um direito, baseada no conceito ampliado de saúde².

Destarte, é importante destacar que por conceito ampliado de saúde compreendese o processo saúde-doença como produto da interação de diversas dimensões, como a biológica, a psicológica, a econômica, a cultural, a social, a individual, a coletiva, entre outras ${ }^{7}$. Assim, determinados grupos seriam mais vulneráveis ao adoecimento do que outros, quando se leva em conta suas condiçóes de vida, em decorrência dos chamados determinantes sociais da saúde. Esses determinantes póem em evidência a complexidade inerente ao campo da saúde, bem como as diferentes dimensões que a circunscrevem. Logo, a partir do conceito ampliado da saúde, o objeto das suas práticas ultrapassa a doença, envolve diferentes equipes de profissionais e agrega conhecimentos de diferentes disciplinas, em um processo interdisciplinar e interprofissional.

\section{Interdisciplinaridade: a cooperação de saberes para ampliar o olhar}

A interdisciplinaridade surge em resposta à diversidade, à complexidade e à dinâmica do mundo atual e, apesar da contemporaneidade da discussão, não é uma proposta recente ${ }^{8}$.

Desde os anos de 1960, a proposta interdisciplinar tem sido apontada como alternativa à produção de conhecimento na busca de respostas não encontradas nos moldes do conhecimento simplificador, dicotômico e disciplinar da ciência moderna $^{3}$. O reconhecimento das limitaçóes apresentadas pelo paradigma simplista ao desenvolvimento científico - que, segundo Almeida-Filho ${ }^{5}$, teria exaurido a capacidade de apreensão da complexidade das realidades concretas da natureza, da história e das culturas humanas - reivindica a interdisciplinaridade que: "[...] ao invés de se apresentar como alternativa para substituição de um jeito de produzir e transmitir conhecimento, se propõe a ampliar a nossa visão de mundo, de nós mesmos e da realidade, no propósito de superar a visão disciplinar"9 (p. 527).

Mas sobre o que estamos falando quando nos referimos à interdisciplinaridade?

Para melhor responder essa questão, recorremos primeiramente à definição de disciplinaridade, que, de acordo com Japiassu ${ }^{10}$, é a exploração científica especializada de determinado domínio homogêneo de estudo, ou seja, um conjunto específico de conhecimentos que tem características próprias, seja no ensino, na formação, nos métodos ou nas matérias ${ }^{3}$. A compreensão da interdisciplinaridade, no entanto, não possui uma única concepção. Ela incorpora uma grande diversidade de configuraçóes quando se considera suas distintas finalidades: como troca de saberes entre campos disciplinares distintos, como campo teórico para questionar a fragmentação disciplinar do saber nas instituiçôes, como forma alternativa ao desenvolvimento de pesquisa e tecnologia, ou como ferramenta à formação de profissionais com visão ampla a fim de desenvolver atuação em equipe ${ }^{11}$.

Consideramos neste trabalho uma perspectiva mais abrangente para compreender a interdisciplinaridade (ilustrada na figura 1), definindo-a como qualquer processo, seja no ensino, pesquisa ou extensão, que associe, em torno da observação de um mesmo objeto científico ou do tratamento de uma questão em comum, vários saberes - leiamse também campos disciplinares ou especialidades - reconhecidos como distintos pela instituição acadêmica, de modo a ser possível superar a simples justaposição 
desses saberes. Isso ocorre de modo a resultar em intercâmbios, flexibilidade e enriquecimentos mútuos que permitam estruturar abordagens que não pertencem a nenhum dos campos de origem. É, antes de tudo, o produto exclusivo da cooperação e da diversidade de olhares ${ }^{3,11,12}$.

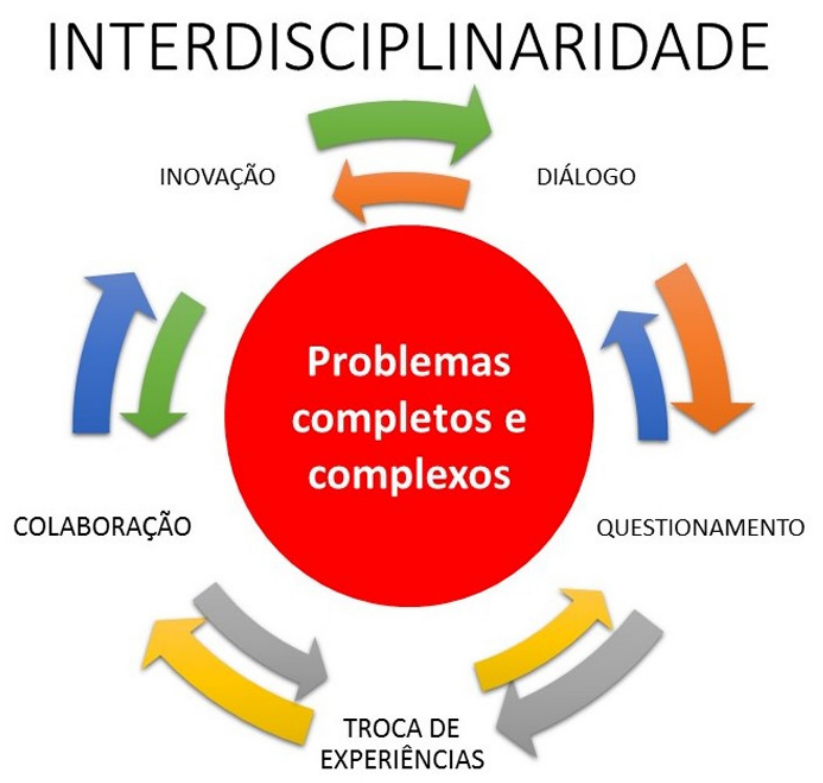

Figura 1. Representação esquemática do fazer interdisciplinar a partir do conceito de interdisciplinaridade adotado neste trabalho. As setas coloridas representam distintos campos disciplinares e apontam para as contribuições que a interação entre as disciplinas pode oferecer na busca de soluções aos problemas.

Fonte: Elaboração dos autores, 2019.

Longe de ser um caminho mágico para a solução de todos os problemas não resolvidos pela ciência moderna, a proposta interdisciplinar é antes um desafio, que, em função de um questionamento compartilhado, tende à convergência com reciprocidade, mútuo enriquecimento e aprendizagem conjunta entre os indivíduos que interagem interdisciplinarmente ${ }^{13}$. $O$ desafio é esse: romper com o processo de troca de competências, no qual cada saber atua sobre uma face de determinado problema, pela troca de experiências, promovida pela multiplicidade de questionamentos e olhares dos distintos saberes, capaz de ampliar a compreensão desse problema e propor soluçóes conjuntas, levando em conta a complexidade de sua completude.

A partir dessa leitura e reflexão surgem alguns questionamentos: Como fazer que os conceitos aqui apresentados ultrapassem o plano epistemológico e sejam operacionalizados na realidade da atuação profissional? Qual ou quais os desafios $\mathrm{da}$ universidade nesse contexto? Será que a formação acadêmica contemporânea tem dado conta de aproximar os estudantes à compreensão da natureza complexa da realidade e da saúde? 


\section{A interprofissionalidade na formação de novos perfis profissionais}

Não são poucas as mudanças necessárias até que seja possível implementar uma abordagem eficiente à complexidade dos objetos e conceitos que constituem a saúde ${ }^{13}$, e o processo de formação acadêmica configura-se como uma dimensão fundamental. Nesse cenário, a interprofissionalidade tem buscado superar a fragmentação estruturante das instituiçóes formadoras e dos currículos acadêmicos, uma vez que a lógica uniprofissional não tem sido capaz de formar profissionais aptos a atuarem diante dos novos problemas da sociedade, considerando a natureza heterogênea dos fenômenos e necessidades de saúde.

O fato é que a interprofissionalidade, por si só, não é capaz de conduzir toda essa complexidade, apesar de ter servido de subsídio para a compreensão da necessidade de mudança. Conforme descrito por Peduzzi et $\mathrm{al}^{14}$, ela permite o desenvolvimento da aprendizagem compartilhada e da atuação integrada em equipe; o reconhecimento da interdependência; a realização de práticas colaborativas; e a melhoria na prestação de serviços e na qualidade do cuidado.

Há, no entanto, duas importantes dificuldades a serem superadas a fim de aproximar a interprofissionalidade da formação acadêmica: a valorização de uma formação uniprofissional e a efemeridade das ações de educação interprofissional ${ }^{14}$. Tal realidade não é muito discrepante das dificuldades enfrentadas na consolidação da interdisciplinaridade, devido à presença marcante da disciplinaridade na conformação das matrizes curriculares, à organização departamental das instituiçóes, à resistência dos docentes na flexibilização de seus domínios intelectuais, à legitimação da especialização precoce e do trabalho especializado pelos acadêmicos e ao pensamento hegemônico dicotômico e fragmentador dominante na sociedade ${ }^{15}$.

Apesar de tais obstáculos, tem se observado um desenvolvimento significativo de experiências interprofissionais em todo o mundo, com ampliação de sua visibilidade e do seu espaço nas discussóes nos níveis político e acadêmico ${ }^{16,17}$. Barr ${ }^{16}$, ao mapear tais experiências, constatou o pioneirismo de regióes como a Austrália, a Europa e a América do Norte, bem como as ações que começaram a ser desenvolvidas na África e na América do Sul. Os objetivos de tais iniciativas são os mais variados: responder às necessidades locais da população, visando melhorar as relaçóes de trabalho nas equipes de atenção primária e comunitária; estimular a integração entre os serviços de saúde e a assistência social; e implementar estratégias de recursos humanos ou corrigir lacunas existentes no processo de colaboração entre as mais distintas profissóes ${ }^{16}$.

Boa parte dessas açôes é estimulada por entidades como a Organização Mundial da Saúde (OMS), em um contexto mais global, ou por agências regionais como a Organização Pan-Americana de Saúde (Opas) ${ }^{17-19}$. Na América do Sul, por exemplo, a Opas, por meio da resolução CSP 29.R15, de 2017, aprovou sua estratégia de recursos humanos para acesso universal à saúde, na qual incentiva os diferentes países da região a desenvolverem equipes interprofissionais dentro da rede de serviços e a diversificarem os cenários de aprendizagem, com vistas ao intercâmbio de experiências e à cooperação ${ }^{18}$.

Países como Bolívia, Cuba, Chile, Honduras e Peru têm investido em propostas que visam a qualificação docente, respaldados na educação interprofissional; outros, como Argentina e Guiana, têm se dedicado a investigar a temática. Guatemala, Nicarágua, Panamá e Venezuela, por sua vez, voltam-se para a qualificação dos 
profissionais de saúde, embasados nas metodologias e nos aportes teóricos da educação interprofissional ${ }^{17}$.

No cenário brasileiro apesar de haver "um conjunto de experiências ainda tímido" (p. 11) ${ }^{20}$, importantes avanços têm sido alcançados com a incorporação da educação interprofissional no currículo das graduaçóes da área da saúde ${ }^{17}$. Ademais, no Brasil, a educação interprofissional se alinha aos princípios do Sistema Único de Saúde (SUS) e ao seu processo de construção político e social, possuindo, portanto, um caminho promissor $^{16,20}$.

Destacam-se experiências como a da Universidade Federal de São Paulo (Unifesp), campus Baixada Santista, que, em 2006, implantou seu currículo integrado, envolvendo seis cursos, e o desenvolvimento de práticas colaborativas; a da Faculdade de Ceilândia e da Universidade de Brasília (UnB), com cinco cursos de graduação em saúde integrados; e a proposta dos Bacharelados Interdisciplinares, com sua formação em ciclos, presentes em diferentes universidades: Universidade Federal do Sul da Bahia (UFSB), Universidade Federal da Bahia (UFBa), Universidade Federal do Recôncavo da Bahia (UFRB), Universidade Federal do Oeste da Bahia (UFOB), Universidade Federal do $A B C$ (UFABC), entre outras ${ }^{20}$.

Mesmo com esses avanços, o caminho a ser percorrido ainda é longo e requer o envolvimento e articulação de diferentes atores, responsáveis pela formação e pelas políticas de recursos humanos dos futuros profissionais.

\section{Uma experiência de extensão universitária interdisciplinar e interprofissional em uma comunidade assentada no centro-sul da Bahia}

À medida que se desenvolvem conexões e diálogos entre a universidade e a sociedade, a extensão universitária se confronta com diversos problemas sociais que solicitam a cooperação dos mais distintos saberes para sua solução. A extensão, então, tem sido uma estratégia importante para a formação acadêmica e profissional, na medida em que aproxima os estudantes das necessidades individuais e coletivas das comunidades, conduzindo-os a repensarem seus saberes e fazeres quando se deparam com os desafios manifestos na complexidade dessas realidades ${ }^{21}$. Foi assim no assentamento Baixão, do Movimento dos Trabalhadores Rurais Sem Terra (MST).

O Baixão, localizado na cidade de Itaeté (Bahia), foi criado em 1998, com a ocupação de cerca de trezentas famílias sem-terra em uma fazenda no sul do Parque Nacional da Chapada Diamantina. Atualmente, possui cerca de três mil hectares e 140 famílias.

O assentamento possui como principal forma de moradia casas de alvenaria e dispóe de água encanada e energia elétrica, além de dois lotes rurais por família, nos quais é possível desenvolver atividades agrícolas. A comunidade tem uma escola, um campo de futebol, igrejas de diferentes religiôes e uma Unidade de Saúde. Suas principais fontes de renda são a agricultura (com a produção de milho, amendoim, mamona, além de algumas outras hortaliças, leguminosas e frutas) e o turismo rural, bem como atividades de pequenos comércios locais e revenda de produtos feitos pela associação de mulheres do assentamento (com a produção de polpas de fruta e sequilhos).

Ao reconhecer a importância de aproximar a universidade das comunidades, levando-se em conta a necessidade de sensibilizar e mobilizar diversos indivíduos e 
instituições à implementação de ações em torno da garantia do direito à saúde e da melhoria das condiçôes de vida, estruturou-se o programa "A participação social e a garantia do direito à saúde: planejamento intersetorial, arte, mobilização social e educação popular, em uma comunidade da Bahia", financiado pelo Ministério da Educação (MEC) do Brasil. Tal programa visa oferecer ferramentas para o reconhecimento dos direitos sociais dos moradores do assentamento e servir como espaço de formação interdisciplinar e interprofissional aos acadêmicos dos mais diversos cursos de graduação, propondo-se a articular atividades artísticas e o planejamento participativo de ações intersetoriais em saúde, de modo que fosse possível gerar reflexóes sobre a importância da mobilização, tanto nos acadêmicos quanto nos assentados, na busca por melhorias nas condições de vida da população.

As açóes foram desenvolvidas no segundo semestre de 2015 pela Universidade Federal da Bahia (UFBa) vinculadas ao programa de Atividade Curricular em Comunidade e Sociedade (ACCS), em parceria com a Faculdade de Farmácia da Universidade Federal de Sergipe (UFS). O programa se baseou na metodologia da pesquisa-açãa ${ }^{(\mathrm{d})}$ e se estruturou em três etapas:

1 - Reconhecimento da comunidade - Realizou-se uma viagem de reconhecimento da comunidade e levantamento de demandas da população, na qual foi possível identificar informantes-chaves, necessidades de saúde individuais e coletivas, condiçôes de vida dos assentados e suas concepções de saúde. Muitas questôes foram levantadas e diversas situaçóes-problemas foram identificadas pelos moradores, tais como:

Cobertura da atenção primária deficiente - demandando maior esclarecimento sobre doenças prevalentes como hipertensão, diabetes, obesidade, câncer de próstata, doenças sexualmente transmissíveis; poucas alternativas para obtenção de fonte de renda - solicitando ações para o desenvolvimento de artesanatos locais; criação de caprinos, ovinos e peixes; e registro do logotipo do assentamento para agregar valor aos produtos que já são feitos pelas mulheres.

Dificuldade no acesso à educação, o que demanda estratégias para aproximação das escolas técnico-agrícolas da região com o assentamento; e esclarecimento sobre as políticas de permanência estudantil nas universidades e as etapas para ingressar no ensino superior.

Dúvidas referentes a questôes sobre a sexualidade e ao gênero - o que torna necessárias discussóes acerca da homossexualidade e do protagonismo das mulheres daquele lugar e da ausência de coleta dos resíduos produzidos pela comunidade solicitando alternativas para reaproveitamento e descarte adequado do lixo, entre diversas outras questóes.

Essas demandas emergiram por meio da realização de rodas de conversa com a população, observação participante dos membros da equipe de execução, bem como por meio da aplicação de um roteiro socioantropológico, elaborado coletivamente pelos membros da equipe de execução com base nos diversos direitos dos cidadãos brasileiros, como a educação, a saúde, o emprego, a habitação e a renda. Ademais, as informações coletadas foram trianguladas com dados disponíveis em sistemas de informações (SINAN, SIM, SINASC, SIH, Censos do IBGE, entre outros) e Secretarias de níveis federal, estadual e municipal.

\author{
(d) A pesquisa-ação é uma \\ metodologia participativa \\ que possibilita a realização \\ de pesquisa aplicada, \\ orientada para elaboração de \\ diagnósticos, identificação \\ de problemas e busca de \\ soluções por meio da interação \\ dinâmica e dialógica entre \\ pesquisadores e comunidade. \\ Tem-se uma intrínseca relação \\ entre $\mathrm{o}$ ato de pesquisar e as \\ ações desenvolvidas em uma \\ comunidade 22 .
}


2 - Preparação das intervenções - O reconhecimento dessas demandas apontou a necessidade de se organizar ações interprofissionais com estudantes de distintas graduaçóes que pudessem colaborar no planejamento e execução de atividades que abordassem os temas solicitados pela comunidade. Assim, iniciaram-se estudos semanais, durante todo o período de execução do programa, envolvendo todos os participantes, por meio de leitura bibliográfica e discussóes crítico-reflexivas, mediadas pelos docentes apoiadores, acerca dos seguintes temas: interdisciplinaridade e interprofissionalidade; saúde das populações do campo e da floresta; educação popular; promoção da saúde; e movimentos sociais, na perspectiva de fornecer ferramentas teórico-metodológicas aos estudantes no desenvolvimento de suas açóes. Buscouse com essa estratégia garantir que as açóes planejadas, além de serem embasadas no conhecimento vigente, fossem também capazes de propiciar o diálogo; a escuta atenta e qualificada da comunidade; o estímulo à participação social; a valorização dos saberes próprios dos habitantes do assentamento; a construção compartilhada de questionamentos; a autonomia; a criatividade; e o desenvolvimento da consciência crítica, a fim de subsidiar uma atuação que valorizasse não apenas a colaboração entre distintos campos científicos, mas também o encontro e as diversas contribuiçôes resultantes do diálogo com os saberes populares para o enfrentamento dos problemas.

O grupo foi composto por trinta estudantes dos cursos de Nutrição, Filosofia, Bacharelado Interdisciplinar em Saúde (BI Saúde), Medicina, Fisioterapia, Farmácia, Odontologia, Medicina Veterinária e Psicologia, além de sete professores apoiadores. Os docentes envolvidos no programa são professores da UFBa e UFS, com distintas formaçôes profissionais: Medicina, Odontologia, Farmácia, Engenharia Ambiental, Fisioterapia, Bacharelado Interdisciplinar em Saúde e Psicologia. Eles atuaram como facilitadores durante todo o processo, seja na elaboração de estratégias metodológicas, na ação em comunidade ou no processo formativo dos participantes, provocando questionamentos, especialmente no que se refere à limitação disciplinar evidenciada pelos estudantes e a desconexão entre ensinamentos universitários e a realidade social.

As atividades desenvolvidas na comunidade foram elaboradas conjuntamente por todos os discentes participantes. Cada estudante assumiu uma situação-problema, identificada junto com a comunidade na etapa anterior, para a organização de oficinas temáticas, a partir de seu interesse pessoal. O processo de organização envolveu desde o planejamento metodológico da ação a ser desenvolvida até as abordagens que seriam priorizadas em cada tema. Em sala de aula, cada oficina foi apresentada ao grupo de estudantes e docentes, sendo diversas vezes aprimorada a partir das contribuiçóes dos diferentes olhares dos outros participantes que compunham o grupo, de modo que todas as propostas encaminhadas tivessem a colaboração dos mais distintos saberes e que todos os estudantes soubessem como executá-las.

3 - Ação em comunidade - A equipe de execução do programa ficou inserida durante cinco dias na comunidade em tempo integral. As ações aconteceram durante as férias acadêmicas dos discentes. Ao todo, foram desenvolvidas vinte oficinas temáticas. Dentre essas, em decorrência de suas diferentes estratégias nas abordagens dos temas, destacamos seis para melhor caracterização (Quadro 1). Todas as oficinas tiveram caráter participativo e apontavam a necessidade da mobilização e organização para a conquista de direitos, assim como os caminhos para garantir que inúmeras políticas públicas se fizessem presentes no assentamento. Utilizaram-se diversos recursos para 
aproximar as discussóes com a realidade da comunidade, tais como peças teatrais, narrativas com fantoches, simulação das situações cotidianas com os hábitos de vida e alimentação das famílias assentadas, entre outros. Destaca-se em todas as oficinas a presença de estudantes de distintas graduações, a fim de estimular de fato a cooperação, a interdisciplinaridade e interprofissionalidade nas intervençôes.

Quadro 1. Atividades desenvolvidas pelo programa no assentamento

\begin{tabular}{|c|c|c|c|}
\hline Nome da atividade & Estratégia & Objetivos & Público-alvo \\
\hline $\begin{array}{l}\text { Oficina de gincanas, } \\
\text { brincadeiras e desenhos }\end{array}$ & Dinâmicas de grupo & $\begin{array}{l}\text { Promover lazer, criatividade e } \\
\text { entretenimento }\end{array}$ & Infantojuvenil \\
\hline $\begin{array}{l}\text { Como cuidar da pressão } \\
\text { alta e do diabetes? }\end{array}$ & $\begin{array}{l}\text { Roda de conversa } \\
\text { e triagem de } \\
\text { hipertensão e } \\
\text { diabetes }\end{array}$ & $\begin{array}{l}\text { Desenvolver a promoção da saúde; } \\
\text { despertar o autocuidado; prevenir } \\
\text { essas doenças; e garantir o direito à } \\
\text { assistência no SUS }\end{array}$ & Jovens e adultos \\
\hline $\begin{array}{l}\text { Oficina de saúde do } \\
\text { homem }\end{array}$ & $\begin{array}{l}\text { Roda de conversa e } \\
\text { peça de teatro }\end{array}$ & $\begin{array}{l}\text { Dialogar sobre as principais barreiras } \\
\text { para procura e acesso aos serviços } \\
\text { de assistência, bem como as } \\
\text { principais questões sobre o câncer de } \\
\text { próstata e as doenças sexualmente } \\
\text { transmissíveis }\end{array}$ & $\begin{array}{l}\text { Homens do } \\
\text { assentamento }\end{array}$ \\
\hline $\begin{array}{l}\text { A saúde que brota da } \\
\text { terra: cultivo de plantas } \\
\text { medicinais }\end{array}$ & $\begin{array}{c}\text { Atividade de } \\
\text { plantação, cultivo } \\
\text { e manuseio de } \\
\text { plantas medicinais }\end{array}$ & $\begin{array}{l}\text { Compartilhar experiências sobre } \\
\text { a manipulação e uso das plantas } \\
\text { medicinais, disponíveis localmente }\end{array}$ & $\begin{array}{l}\text { Jovens, adultos e } \\
\quad \text { idosos }\end{array}$ \\
\hline $\begin{array}{l}\text { Oficina de mobilização da } \\
\text { juventude: a universidade } \\
\text { está longe de mim? }\end{array}$ & Roda de conversa & $\begin{array}{l}\text { Recuperar a autoestima e a capacidade } \\
\text { de mobilização, bem como apresentar } \\
\text { as políticas de assistência e } \\
\text { permanência estudantil nas instituições } \\
\text { públicas de ensino superior }\end{array}$ & Jovens \\
\hline $\begin{array}{c}\text { Como criar caprinos e } \\
\text { ovinos? }\end{array}$ & $\begin{array}{l}\text { Construção de } \\
\text { painel ilustrativo }\end{array}$ & $\begin{array}{l}\text { Dialogar sobre as alternativas locais } \\
\text { para criação e comercio de animais de } \\
\text { pequeno porte }\end{array}$ & Jovens e adultos \\
\hline
\end{tabular}

Fonte: Elaboração dos autores, 2018.

Desse modo, é importante destacar que o presente trabalho tem por objetivo refletir sobre o potencial da interprofissionalidade e da interdisciplinaridade na formação acadêmica e no processo de consolidação do conceito ampliado em saúde, tomando como base as ações desenvolvidas neste programa de extensão.

\section{Métodos}

Trata-se de um estudo exploratório de abordagem qualitativa que contou com a participação de nove estudantes de diferentes cursos de graduação da UFBa e da UFS.

A seleção dos participantes do estudo foi realizada levando-se em consideração quatro critérios de inclusão: ter participado das atividades desenvolvidas pelo programa durante o segundo semestre de 2015; ter interesse pessoal em participar do estudo; e garantir a participação de um discente de cada graduação envolvida no programa, de modo a se assegurar uma representação equânime entre os diferentes cursos participantes e a identificação das percepçóes e impactos nas diferentes áreas do saber. É relevante destacar que nos casos em que houve mais de um estudante de um mesmo curso apto a participar das entrevistas, coube aos docentes apoiadores selecionarem o 
discente a ser entrevistado, levando-se em consideração os seguintes critérios: adesão às atividades realizadas, desempenho no trabalho de campo, participação nas oficinas preparatórias, comprometimento com o programa e fazer parte de uma das duas instituições de ensino participantes.

Os critérios de exclusão consistiram em: não ter participado da imersão no território; não ter finalizado o diário de campo, no qual deveriam constar reflexões referentes às vivências no programa; e não ter obtido frequência mínima de $75 \%$ nos encontros preparatórios das oficinas.

Após a seleção dos estudantes, ocorrida em meados de novembro de 2015, foi agendada e realizada com cada participante selecionado uma entrevista semiestruturada, tendo como base um roteiro elaborado previamente. As entrevistas foram realizadas, por dois pesquisadores, entre dezembro de 2015 e fevereiro de 2016, e contou com um roteiro, composto por cinco questóes disparadoras que abordavam as temáticas da interdisciplinaridade, da interprofissionalidade, da atuação em comunidade, do compartilhamento de experiências e do trabalho em equipe.

As entrevistas tiveram duração média de trinta minutos, foram gravadas e em seguida transcritas na íntegra. As transcrições compuseram o corpus de análise do presente estudo, que foi apreciado por meio da análise de conteúdo ${ }^{23}$. Na primeira fase, de pré-análise, as transcriçôes foram lidas em sua integralidade e seus dados foram organizados em: curso de graduação do entrevistado; percepção sobre interdisciplinaridade e extensão universitária; percepção sobre o programa de extensão; relatos e análises da experiência; e avaliação da vivência em comunidade e da participação em um programa interprofissional. Essa organização respeitou as regras da "exaustividade, representatividade, homogeneidade, pertinência e exclusividade"23.

Após a pré-análise, o conteúdo foi analisado em profundidade, levando-se em consideração a literatura cientifica atual na busca por conteúdos coerentes, singulares ou contraditórios na fase de exploração do material ${ }^{23}$.

Posteriormente a essa etapa, realizou-se a definição das categorias, de acordo com as informaçôes e análises que emergiram do corpus e procedeu-se à interpretação dos resultados. Os resultados encontrados em cada categoria são apresentados a seguir, cotejados com os aspectos teóricos do seu campo científico, bem como as experiências atuais da área, sendo comprovados por trechos das entrevistas realizadas com os discentes participantes do estudo.

É relevante salientar que a pesquisa teve aprovação do Comitê de Ética em Pesquisa do Instituto de Saúde Coletiva da Universidade Federal da Bahia (ISC/UFBa), parecer no 135.778, respeitando a Resolução no 466/12 do Conselho Nacional de Saúde, que regulamenta as pesquisas envolvendo seres humanos. Foi solicitado Consentimento Livre e Esclarecido dos estudantes para participarem do estudo, garantindo-se a confidencialidade das informações e o seu anonimato.

\section{Resultados e discussão}

Todos os acadêmicos selecionados e convidados para participarem do estudo ( $\mathrm{n}=9$ ) realizaram as entrevistas, sendo, três do gênero masculino e seis do gênero feminino. Cada um dos cursos de graduação, participantes do programa, teve um estudante incluído na pesquisa. 
Participaram oito alunos da UFBa e um aluno da UFS, mantendo a proporção institucional dos participantes do programa.

A moda etária dos participantes foi de 23 anos, sendo distribuídos ao longo do segundo e quarto ano dos seus respectivos cursos de graduação.

Em seguida, apresentam-se as categorias que emergiram do corpus, bem como a discussão com base nos referenciais teóricos.

\section{Temática 1 - Formação acadêmica e extensão universitária}

[...] a minha formação ficou muito mais próxima ao povo, à população, e quanto mais à questão do movimento sem terra, que eu nunca tinha tido essa aproximação antes, então, a meu ver, ficou muito mais humanizada, com certeza à minha formação acrescentou muito. (Sujeito 1)

A formação universitária, bem como a instituição universitária per si, possuem um importante papel econômico, social e político, com a difusão e elaboração de novos conhecimentos ${ }^{24}$. Entretanto, nos últimos anos, diversos pesquisadores têm questionado o modo como as formaçóes vêm sendo desenvolvidas e a universidade é estruturada ${ }^{25-27}$.

A aproximação maior da universidade com a sociedade se faz necessária e a extensão universitária possui relevância nesse sentido, visto que ela se torna um dos caminhos possíveis para se desenvolver uma formação acadêmica emancipadora, que integra teoria e prática, dialoga com a sociedade e possibilita o compartilhamento de saberes entre todos os envolvidos.

[...] esta foi uma das poucas vezes, durante os meus quatro anos de graduação, que eu pude perceber de que modo o que estudo na universidade pode ser utilizado verdadeiramente na prática. Pude perceber de que forma posso atuar na sociedade, posso ser um agente de mudança, valorizando e aplicando meus conhecimentos, mas também valorizando os saberes e as experiências dos outros. (Sujeito 2)

Os resultados encontrados demonstram que, segundo os estudantes, a vivência nas atividades de extensão possibilitou um maior contato deles com a realidade, aspecto fundamental para as suas futuras atuações enquanto profissionais, bem como para modificações em seus papéis e ações de cidadãos. A relação entre universidade e sociedade, a intersecção e o compartilhamento de saberes entre esses dois espaços possibilitam verdadeiras mudanças pessoais, que modificam a forma como o sujeito observa e percebe o mundo a sua volta. Diversos estudos corroboram esse entendimento ${ }^{24,28-30}$ destacando que a extensão possui uma exímia capacidade de transformar a percepção dos envolvidos, afetando seus “territórios existenciais”31.

Se eu pudesse utilizar uma palavra para definir esse programa, diria mudança. Não apenas mudança da realidade dos outros que dele se beneficiaram, como a comunidade, mas uma mudança minha, uma mudança pessoal. A forma como 
eu enxergava os assentados, os estudantes de alguns outros cursos, e até a minha profissão, meu lugar no mundo, certamente não é mais o mesmo. (Sujeito 7)

Outros aspectos também são citados pelos estudantes participantes da pesquisa: uma maior aproximação deles com a comunidade; uma maior capacidade de escuta, de se colocar no lugar do outro; maior contato com a realidade e com os problemas sociais; reconhecimento do seu papel de cidadão e de agente transformador da sociedade; capacidade de dialogar e trabalhar com diferentes atores sociais; interação da teoria com a prática, de modo que os conhecimentos adquiridos na universidade sejam usados para garantir respostas às demandas sociais; e planejamento e desenvolvimento de novas metodologias de trabalho e ensino.

Tais aspectos modificam o modo como os estudantes enxergam o mundo e se portam perante ele. Mudanças são, portanto, necessárias na prática do próprio indivíduo, que passa a ressignificar a sua formação e a desenvolver novos comportamentos, sejam eles na dimensão pessoal ou acadêmica. Os discentes sinalizaram que em diversos momentos foram estimulados a refletir sobre o seu processo formativo e sua relação com o outro, sendo inúmeras vezes necessário readaptar suas práticas e comportamentos provenientes de sua formação no meio universitário.

\section{Temática 2 - Elementos da vivência que serão aplicados na prática profissional}

O saber ouvir o que eles têm a dizer eu acho que isso foi o que eu mais aprendi. Eu vou levar para a minha vida quando eu tiver atendendo, quando eu tiver me comunicando. É saber ouvir o que eles têm a dizer e não questionar, não impor, não dizer "você está errado e eu estou certa, eu sou dono da razão". Sempre tentar achar uma solução intermediária entre o que pra mim é certo e do que pra ele é o certo. Não querendo que eu seja a dona da razão e nem ele. (Sujeito 1)

Diversos cursos de graduação na área da saúde buscam elaborar currículos e metodologias nas quais os egressos/profissionais possam ter acesso a uma formação generalista, humanista, crítica e reflexiva para atuar em todos os níveis de atenção à saúde, como preconizam as diretrizes curriculares ${ }^{32,33}$. Entretanto, apesar desse intuito, o contato dos alunos com as comunidades ainda é escasso, as atividades práticas se mostram distantes da realidade e as vivências com metodologias ativas, nas quais o aluno reflete sobre suas açóes, sobre a realidade e seu papel na sociedade, mostram-se complexas ou inexistentes, devido a uma gama de obstáculos que perpassa desde os aspectos institucionais até os elementos subjetivos dos próprios docentes e coordenadores de cursos $^{34-36}$.

A despeito de existirem essas adversidades, inúmeras competências são necessárias para se trabalhar no campo da saúde, visto que em diferentes momentos é imprescindível mobilizar conhecimentos, esquemas e vivências prévias para o desenvolvimento de respostas criativas e flexíveis para as situações do cotidiano. Assim, fazem-se necessárias, por exemplo, a escuta qualificada, a empatia, a utilização adequada 
da linguagem de acordo com o público e a capacidade de trabalhar em equipe e de analisar de forma ampla os problemas identificados ${ }^{37,38}$. É importante enfatizar que tais competências não se restringem apenas aos profissionais da saúde, sendo necessárias também em outros campos do conhecimento.

De acordo com os resultados encontrados, a realização das atividades de extensão tem propiciado uma formação na qual os estudantes desenvolvem as competências mencionadas e muitas vezes reorientam a sua formação profissional. Isso se dá tanto por meio de mudanças pessoais quanto de um maior questionamento acerca da estrutura curricular na qual seu curso se enquadra, bem como pela ocupação de espaços de decisão, como colegiados de cursos de graduação, representações estudantis, entre outros, visando uma formação que seja capaz de favorecer a relação profissionalusuário, buscando entender e valorizar as vivências, realidades e conhecimentos de todos, como destaca um dos discentes:

[...] pelo menos no meu curso, na Fisioterapia, eu vejo isso: a gente é ensinado a só entregar o conhecimento pronto pra pessoa, e lá eu tive a oportunidade de fazer o inverso; eu tive a oportunidade de ouvir e, dessa forma, compreendendo o cenário, eu posso fazer minha terapêutica, no caso, o que eu tava ali para fazer. (Sujeito 7)

Assim, o contato com a comunidade torna-se elemento disparador para o desenvolvimento de adaptaçôes relacionais e incentivo a mudanças nas projeçôes de atuação profissional dos discentes. De acordo com os depoimentos analisados, as vivências tocam o indivíduo, modificam o seu ser, seus ideais e atitudes. Ao entrar em contato com uma realidade que não é igual a sua, o discente relaciona-se com diferentes "territórios existenciais" e precisa, portanto, respeitar as singularidades e aprender a arte do diálogo, modificando-se e afetando o outro em um verdadeiro processo de poiesi ${ }^{39}$.

Entender o que o outro passa, entender a realidade do outro, essa imersão mesmo de conviver e se colocar no lugar do outro para só assim saber o que compartilhar e o que conversar mesmo. Saber a linguagem dele, porque não adianta eu estar falando em uma linguagem sem saber se o outro está me ouvindo, sem saber se o outro está me entendendo ou não. Então, a partir do momento que eu sento com uma pessoa de outra realidade, que eu começo a entender como é que ele anda no mundo, eu vou ter a capacidade de que ele me ouça mais e até compartilhe mesmo, eu aprendo com ele, e ele comigo e viceversa. (Sujeito 6)

Diferentes competências desenvolvidas na ação extensionista são destacadas pelos discentes como de grande potencial para serem reproduzidas posteriormente no campo de trabalho ou nas relaçóes interpessoais, a exemplo da escuta qualificada, do respeito e da empatia. Ademais, os discentes mostram-se mais críticos, passam a questionar o mundo, a sua formação e principalmente começam a repensar a sua futura prática.

Eu acho que a experiência em si foi uma experiência diferente, foi um fazer diferente, foi uma oportunidade de estar com o outro e não está só prescrevendo 
àquele outro, mas estar com esse outro construindo um conhecimento. E isso é muito importante na minha prática médica porque eu vou fazer uma prática médica diferente. Eu tento já, com os elementos que eu já construí que eu fui construindo durante todo o semestre, fazer uma prática médica diferente, uma prática médica mais atenta a esse outro, que eu possa escutá-lo mais, dar um sentido para aquilo que eu vou prescrever. (Sujeito 3)

Tais transformações tornam-se ainda maiores quando as atividades extensionistas envolvem açóes interprofissionais, uma vez que os discentes devem aprender a relacionar os seus conhecimentos e crenças com as das demais áreas. Além do mais, eles são estimulados a respeitar as percepçóes diferentes das sua, completando-as e analisando as diversas formas de interpretação de um mesmo evento.

Assim, a inserção dos discentes em atividades de extensão interprofissionais e interdisciplinares pode propiciar que esses compreendam a horizontalização dos saberes, baseada em uma "axiomática geral compartilhada", ou conjuntos de valores e princípios comuns, que, apesar de serem originados em diferentes áreas, orientam as ações e buscam a solução de uma determinada questão ${ }^{33}$.

\section{Temática 3 - Interprofissionalidade e interdisciplinaridade}

Apesar de ser o cerne dos aspectos mencionados, o fazer interprofissional e interdisciplinar ainda se mostra incipiente na formação de boa parte dos estudantes participantes da ACCS. Tal aspecto é analisado criticamente pelos discentes participantes, que destacam a necessidade de uma reformulação no modelo pedagógico, de modo que este possa conceber espaços propícios a uma maior aproximação da universidade com a sociedade, bem como o intercâmbio e reformulação de saberes por intermédio da interprofissionalidade.

[...] até agora a minha grade curricular do curso de filosofia não me proporcionou nenhuma atividade interdisciplinar, então eu fiquei com esse ganho que eu até digo lá ao pessoal quando me perguntam o que é que eu fiz esse semestre, como é que foi a ACCS que eu, fiz eu digo: se eu não fizesse essa ACCS, eu nunca teria oportunidade de ir para uma comunidade fora da universidade como eu fui com essa ACCS. (Sujeito 5)

É notória na literatura científica a necessidade de se repensar a formação e os currículos no campo universitário, ainda mais na área da saúde, devido às constantes demandas do SUS, que requerem profissionais com atuação interprofissional e que respeitem os seus princípios, atuando com responsabilidade integral sobre a saúde da população em um determinado território ${ }^{40}$.

[...] essa foi uma das poucas vezes em que pude aprender com alunos de outros cursos, conhecer um pouco mais sobre sua formação, pensar junto com o outro, de outra área, sobre um mesmo problema, compartilhar informaçóes, colaborar com o trabalho do outro. (Sujeito 8) 
Há, portanto, a necessidade de construção de espaços em que as diferentes formas de saber possam dialogar, em que as diversas profissóes possam compartilhar informaçốes e pensar e repensar uma determinada realidade.

A elaboração e execução de diferentes etapas desse programa, de forma compartilhada, como descritas anteriormente, puderam favorecer a prática colaborativa e o aprendizado mútuo entre os sujeitos. Esse processo deu-se desde a elaboração do roteiro socioantropológico, na primeira etapa, utilizado para a identificação das questões-problemas, até o planejamento e a realização das oficinas de trabalho, durante a imersão no campo.

Ao longo da elaboração do roteiro socioantropológico, os discentes puderam conhecer/reconhecer direitos e temas relevantes em outras profissóes, que muitas vezes não são trabalhados em sua área, ou, caso o sejam, não têm a relevância adequada. Como exemplo, tem-se a Saúde Bucal, um tema constantemente trabalhado pelos discentes de Odontologia, mas negligenciados ou minimizados em outras graduaçóes da área da Saúde, como Medicina e Fisioterapia.

Já no que se refere às oficinas, tanto o seu planejamento quanto a sua execução, estimularam a prática colaborativa. As questões-problemas foram apresentadas e os discentes das diferentes graduações as analisaram, explicitando as suas percepções e as possíveis soluçóes dentro de sua área. Esse processo conjunto de análise de uma dada realidade favoreceu o aprendizado mútuo, de modo que uma solução/ação pudesse emergir do diálogo e convergisse as diferentes proposiçóes. Assim, houve um intenso processo de aprendizado, como destacamos por meio do seguinte excerto: "pensar junto uma realidade, discutir proposiçôes, entender e valorizar o conhecimento do outro, aliar objetivos diferentes foi um intenso processo de aprendizagem” (Sujeito 7).

Para além dessas práticas colaborativas, é importante destacar que ainda na primeira fase do programa diversos aportes teóricos foram discutidos coletivamente com os discentes, de modo que todos pudessem desenvolver competências comuns, como a escuta qualificada e o respeito pela opinião/visão do outro.

Por conseguinte, há uma necessidade de equilíbrio entre a excelência técnica da formação profissional e a sua relevância social, com modelos pedagógicos mais interativos, centrados nos alunos e respaldados na realidade social ${ }^{41}$. É indispensável a construção de currículos com atividades extramurais em unidades do SUS, ou em comunidades com graus crescentes de complexidade e que envolvam sujeitos de diferentes áreas do saber.

Entretanto, como destaca Almeida-Filho ${ }^{42}$, parafraseando Milton Santos, o caminho de transformação é complexo e envolve alguns obstáculos: burocratização e institucionalismo, inércia e conservadorismo. Todavia, não devemos sucumbir: é necessário exercitar a criatividade e encontrar possíveis saídas, e nesse cenário a extensão universitária mostra-se de exímia importância. Um grande avanço foi dado com o Plano Nacional de Educação ${ }^{43}$, em 2014, e mais recentemente com a Resolução nº 7, de 18 de dezembro de 2018, do Ministério da Educação, que estabelece as Diretrizes para a Extensão na Educação Superior Brasileira e institui que "as atividades de extensão devem compor, no mínimo, $10 \%$ (dez por cento) do total da carga horária curricular estudantil dos cursos de graduação, as quais deverão fazer parte da matriz curricular dos cursos” (p. 49) ${ }^{44}$. É necessário que tal obrigatoriedade seja cumprida e fiscalizada; além disso, é importante que se considere a natureza das atividades de extensão, a 
serem desenvolvidas de modo que elas sejam capazes de aproximar a sociedade da universidade, estimular a conformação de redes solidárias, propiciar a reflexão crítica dos discentes sobre a realidade e, mais do que isso, garantir uma formação cidadã e emancipadora.

\section{Conclusões}

Por meio desse programa, foi possível perceber que a extensão pode ser um importante instrumento de transformação social e cidadã. A possibilidade de se construir espaços nos quais os futuros profissionais possam interagir de forma dialógica entre si e com uma comunidade mostra-se como um caminho para o desenvolvimento de sujeitos comprometidos com a melhoria das condiçóes de vida e que atuem efetivamente na garantia dos direitos de todos.

Mediante o desenvolvimento das atividades, foi possível perceber que o programa foi capaz de aproximar os estudantes da realidade de saúde do assentamento, possibilitando a utilização de ferramentas da comunicação, do cuidado centrado na promoção da saúde, do diálogo de saberes e da atuação interprofissional para o enfrentamento das demandas em saúde em toda sua complexidade.

Assim, torna-se evidente que as atividades e programas de extensão que se baseiam na interdisciplinaridade e na interprofissionalidade proporcionam trocas de experiências entre os acadêmicos e as comunidades, a construção de relações horizontais nos encontros entre os saberes populares e científicos e o empoderamento dos sujeitos, a fim de superar as iniquidades sociais.

É relevante ressaltar que os resultados aqui apresentados dizem respeito às opinióes expressas por apenas um discente de cada curso de graduação, geralmente aquele com maior atuação nas atividades do programa, o que pode ser, portanto, um viés, já que a opinião deste pode divergir da dos demais, e o impacto de uma ação extensionista depende dos mundos existenciais de cada sujeito. Todavia, tal aspecto não minimiza a importância desse trabalho, ao analisar as ações interprofissionais e interdisciplinares de uma ação extensionista, levando em consideração a sua relevância para uma formação respaldada no conceito ampliado de saúde.

Estudos desse tipo devem ser replicados, com um número maior de participantes e uma diversidade mais significativa de instituiçôes de diferentes regióes brasileiras e de cursos de graduação e pós-graduação, de modo a aferir e analisar os impactos das ações extensionistas de cunho interprofissional e interdisciplinar na formação dos discentes.

\section{Contribuições dos autores}

Todos os autores participaram ativamente de todas as etapas de elaboração do manuscrito. 


\section{Agradecimentos}

À Secretária de Educação Superior do Ministério da Educação, pelo financiamento das ações, por meio do seu Programa de Extensão Universitária (ProExt). À Pró-Reitoria de Extensão da Universidade Federal da Bahia, pela concessão de bolsas de extensão, por meio do seu Programa Institucional de Bolsas de Iniciação à Extensão Universitária (PIBIEX) e das Atividades Curriculares em Comunidade e Sociedade (ACCS).

\section{Direitos autorais}

Este artigo está licenciado sob a Licença Internacional Creative Commons 4.0, tipo BY (https://creativecommons.org/licenses/by/4.0/deed.pt_BR).

(cc)

\section{Referências}

1. Brasil. Ministério da Saúde. VIII Conferência Nacional de Saúde: relatório final. Brasília: Ministério da Saúde; 1986.

2. Batistela C. Abordagens contemporâneas do conceito de saúde. In: Fonseca AF, Corbo $\mathrm{AD}$, organizadores. O território e o processo saúde-doença. Rio de Janeiro: Fiocruz, Escola Politécnica de Saúde Joaquim Venâncio; 2007. p. 51-86.

3. Alvarenga AT, Philippi JA, Sommerman A, Alvarez MAS, Ferdandes V. Histórico, fundamentos filosóficos e teórico-metodológicos da interdisciplinaridade. In: Philippi JA, Neto AJS, editores. Interdisciplinaridade em ciência, tecnologia e inovação. Barueri: Manole; 2011. p. 3-68.

4. Paim JS, Almeida Filho N. Saúde coletiva: uma "nova saúde pública” ou campo aberto a novos paradigmas? Rev Saude Publica. 1998; 32(4):299-316.

5. Almeida Filho N. Transdisciplinaridade e o paradigma pós-disciplinar na saúde. Saude Soc. 2005; 14(3):30-50.

6. Frenk J, Lincoln C, Zulfiqar AB, Jordan C, Nigel C, Timothy E, et al. Health professionals for a new century: transforming education to streng then health systems in an interdependent world. Lancet. 2010; 376(9756):1923-58.

7. Silva JPV, Batistella C, Fonseca MLG. Problemas, necessidades e situação de saúde: uma revisão de abordagens para a reflexão e ação da equipe de saúde da família. In: Fonseca $\mathrm{AF}$, organizador. O território e o processo saúde-doença. Rio de Janeiro: EPSJV/Fiocruz; 2007. p. 159-76.

8. Gomes R, Deslandes SF. Interdisciplinaridade na saúde pública: um campo em construção. Rev Lat Am Enfermagem. 1994; 2(2):103-14.

9. Vilela EM, Mendes IJM. Interdisciplinaridade e saúde: estudo bibliográfico. Rev Lat Am Enfermagem. 2003; 11(4):525-31.

10. Japiassu H. Interdisciplinaridade e patologia do saber. Rio de Janeiro: Imago; 1976.

11. Raynaut C, Zanoni M. Reflexôes sobre os princípios de uma prática interdisciplinar na pesquisa e no ensino superior. In: Philippi JA, Neto AJS, editores. Interdisciplinaridade em ciência, tecnologia e inovação. Barueri: Manole; 2011. p. 143208. 
12. Minayo MCS, organizador. Pesquisa social: teoria método e criatividade. 21a ed. Petrópolis: Vozes; 2002.

13. Almeida Filho N. Intersetorialidade, transdisciplinaridade e saúde coletiva: atualizando um debate em aberto. RAP (Rio de Janeiro). 2000; 34(6):9-32.

14. Peduzzi M, Norman IJ, Germani ACCG, Silva JAM, Souza GC. Educação interprofissional: formação de profissionais de saúde para o trabalho em equipe com foco nos usuários. Rev Esc Enferm USP. 2013; 47(4):977-83.

15. Philippi Junior A, Silva Neto A, editores. Interdisciplinaridade em ciência, tecnologia \& inovação. Barueri: Manole; 2011.

16. Barr H. Interprofessional education: the genesis of a global movement. London: Centre for Advancement of Interprofessional Education; 2015.

17. Silva FAM, Cassiani SHDB, Freire Filho JR. The PAHO/WHO Regional Network of Interprofessional Health Education. Rev Lat Am Enfermagem. 2017; 26(1):1-2.

18. Pan American Health Organization. Strategy on human resources for universal access to health and universal health coverage. Washington: PAHO; 2017.

19. World Health Organization. Framework for action on interprofessional education \& collaborative oractice. Geneva: WHO; 2010.

20. Camara AMC, Cyrino AP, Cyrino EG, Azevedo GD, Costa MV, Bellini MIB, et al. Educação interprofissional no Brasil: construindo redes formativas de educação e trabalho em saúde. Interface (Botucatu). 2016; 20(56):5-8.

21. Almeida DS. Extensão Universitária na UFBA: ACC e a formação do estudante [dissertação]. Salvador: Universidade Federal da Bahia; 2015.

22. Tripp D. Pesquisa-ação: uma introdução metodológica. Educ Pesqui. 2005; 31(3):44366.

23. Bardin L. Análise de conteúdo. 6a ed. São Paulo: Edições 70; 2011.

24. Rios DRS, Caputo MC, Teixeira CF. A extensão universitária e o reconhecimento do direito a saúde: universidade e escola. In: Caputo MC, Teixeira CF, organizadores. Universidade e sociedade concepções e projetos de extensão universiária. Salvador: Edufba; 2014. p. 267-81.

25. Santos BS, Almeida Filho N. A Universidade no século XXI: para uma universidade nova. 3a ed. Coimbra: Almedina; 2008.

26. Silva WR. A construção da interdisciplinaridade no espaço complexo de ensino e pesquisa. Cad Pesqui. 2011; 41(1):582-605.

27. Teixeira AS. Ensino Superior no Brasil: análise e interpretação de sua evolução até 1969. Rio de Janeiro: UFRJ; 2005.

28. Ribeiro KSQS. A contribuição da extensão comunitária para a formação acadêmica em fisioterapia. Fisioter Pesqui. 2005; 12(3):22-9.

29. Fadel CB, Bordin D, Kuhn E, Martins LD. O impacto da extensão universitária sobre a história de vida de acadêmicos de odontologia. Interface (Botucatu). 2013; 17(1):93746.

30. Moura LFAD, Piauilino RJB, Araujo IF, Moura MS, Lima CCB, Evangelista LM, et al. Impacto de um projeto de extensão universitária na formação profissional de egressos de uma universidade pública. Rev Odontol. 2012; 41(1):348-52.

31. Rolnik S. Cartografia sentimental: transformações contemporâneas do desejo. Porto Alegre: EdUFRGS; 2006. (Coleção Cartografias). 
32. Rossoni E, Lampert J. Formação de profissionais para o Sistema Único de Saúde e as diretrizes curriculares. Bol Saude. 2004; 18:87-98.

33. Furlanetto DLC, Bastos MM, Silva Junior JW, Pinho DLM. Reflexóes sobre as bases conceituais das Diretrizes Curriculares Nacionais em cursos de graduação em saúde. Comun Cienc Saude. 2014; 25(2):193-202.

34. Mesquita SKC, Meneses RMV, Ramos DKR. Metodologias ativas de ensino/ aprendizagem: dificuldades de docentes de um curso de enfermagem. Trab Educ Saude. 2016; 14(2):473-86.

35. González $\mathrm{AD}$, Almeida MJ. Ativação de mudanças na formação superior em saúde: dificuldades e estratégias. Rev Bras Educ Med. 2010; 34(2):238-46.

36. Mitre SM, Siqueira-Batista R, Girardi-de-Mendonça JM, Morais-Pinto NM, Meirelles $\mathrm{CAB}$, Pinto-Porto $\mathrm{C}$, et al. Metodologias ativas de ensino-aprendizagem na formação profissional em saúde: debates atuais. Cienc Saude Colet. 2008; 13 Suppl 2:2133-44.

37. Mitre SM, Andrade EIG, Cotta RMM. Avanços e desafios do acolhimento na operacionalização e qualificação do Sistema Único de Saúde na Atenção Primária: um resgate da produção bibliográfica do Brasil. Cienc Saude Colet. 2012; 17(8):2071-85.

38. Lima RCD. SUS e as Teias de Diálogos (im)pertinentes para transformar a formação dos trabalhadores de saúde com vistas à humanização das práticas. Interface (Botucatu). 2009; 13 Suppl 1:789-91.

39. Ayres JRCM. Cuidado: trabalho e interação nas práticas de saúde. Rio de Janeiro: CEPES, CUERJ/IMS, ABRASCO; 2009.

40. Silva VO, Santana PMMA. Conteúdos curriculares e o Sistema Único de Saúde (SUS): categorias analíticas, lacunas e desafios. Interface (Botucatu). 2014; 19(52):121-32.

41. Feuerwerker LCM, Sena RA. Construção de novos modelos acadêmicos de atenção à saúde e de participação social. In: Almeida MJ, Feuerwerker LCM, Llanos MA. Educação dos profissionais de saúde na América Latina: teoria e prática de um movimento de mudança. São Paulo: Hucitec; 1999. p. 47-83.

42. Almeida-Filho, N. Interdisciplinaridade na Universidade Nova: desafios para a docência. In: Gicele C, Rita R, organizadores. Docência Universitária: concepçóes, experiências e dinâmicas de investigação. Xanxerê: Meta Editora; 2014. p. 21-8.

43. Brasil. Presidência da República. Lei no $13.005 / 2014$. Aprova o Plano Nacional de Educação - PNE e dá outras providências [Internet]. Brasília, DF; 2014. [citado 9 Jun 2018]. Disponível em: http://pne.mec.gov.br/18-planos-subnacionais-deeducacao/543-plano-nacional-de-educacao-lei-n-13-005-2014

44. Brasil. Ministério da Educação. Conselho Nacional de Educação. Câmara de Educação Superior. Resolução no 7, de 18 de Dezembro de 2018. Estabelece as Diretrizes para a Extensão na Educação Superior Brasileira e regimenta o disposto na Meta 12.7 da Lei no 13.005/2014, que aprova o Plano Nacional de Educação - PNE 2014-2024 e dá outras providências [Internet]. Brasília, DF: Ministério da Educação; 2018. [citado 20 Fev 2019]. Disponível em: http://www.in.gov.br/materia/-/asset_publisher/ Kujrw0TZC2Mb/content/id/55877808/do1-2018-12-19-resolucao-n-7-de-18-dedezembro-de-2018-55877677 
This article discusses the importance of interdisciplinary and interprofessional health education, based on the understanding that it is not possible to achieve a broad perspective of health through disciplinary and uniprofessional teaching. An exploratory qualitative study was conducted with students from two universities participating in an extension activity in an agricultural reform settlement in the State of Bahia, Brazil. Data was collected via semi-structured interviews and analyzed using content analysis. The findings show that extension activities have the potential to transform the education and training process from both a professional and personal perspective. It was concluded that extension activities enable the construction of new spaces where it is possible to promote interaction between and sharing of knowledge and collaboration.

Keywords: Community-institution relations. Interdisciplinary practices. Higher education.

El presente artículo discute la importancia de la interdisciplinariedad y de la interprofesionalidad en el proceso de formación en salud, partiendo de la comprensión de que no es posible hacer realidad una visión amplia de la salud en los moldes del conocimiento disciplinario y uniprofesional. Se trata de una investigación exploratoria de abordaje cualitativo basada en entrevistas semiestructuradas realizadas con discentes de dos universidades, participantes de una actividad de extensión realizada en el Asentamiento Baixão, localizado en la región centro sur del Estado de Bahia. El análisis de los datos utilizó la metodología del análisis de contenido. A partir de las entrevistas se entiende que las actividades de extensión tienen el potencial de transformar el proceso formativo de sujetos envueltos, ya sea en sus aspectos profesionales o personales. Se concluyó que las acciones de extensión posibilitan la construcción de nuevos espacios en donde es posible desarrollar la interacción y compartición de saberes, así como prácticas colaborativas.

Palabras clave: Relaciones comunidad-institución. Prácticas interdisciplinarias. Enseñanza superior. 